Research Article

\title{
Research and Application of Intelligent Monitoring System Platform for Safety Risk and Risk Investigation in Urban Rail Transit Engineering Construction
}

\author{
Yong Wu $\mathbb{D}^{1},{ }^{1,2}$ Liang-Yun Zhao, ${ }^{3}$ Ye-Xiang Jiang, ${ }^{3}$ Wei Li, ${ }^{3}$ Ye-Sheng Wang $\left(\mathbb{D},{ }^{1,2}\right.$ \\ Huan Zhao, ${ }^{4}$ Wei Wu, ${ }^{4}$ and Xiong-Jian Zhang ${ }^{4}$ \\ ${ }^{1}$ Powerchina Huadong Engineering Co. Ltd., Hangzhou 310014, China \\ ${ }^{2}$ Engineering Research Center of Smart Rail Transportation of Zhejiang Province, Hangzhou 310014, China \\ ${ }^{3}$ Hangzhou Metro Group Co. Ltd., Hangzhou 310020, China \\ ${ }^{4}$ Zhejiang Huadong Mapping and Engineering Safety Technology Co. Ltd., Hangzhou 310014, China
}

Correspondence should be addressed to Ye-Sheng Wang; wang_yc2@ecidi.com

Received 22 March 2021; Accepted 9 August 2021; Published 13 September 2021

Academic Editor: Xin-Jiang Wei

Copyright $\odot 2021$ Yong Wu et al. This is an open access article distributed under the Creative Commons Attribution License, which permits unrestricted use, distribution, and reproduction in any medium, provided the original work is properly cited.

In recent years, the construction scale of urban rail transit project is still in a high growth stage. In addition, the geology and surrounding environment of crossing lines are complex, and all kinds of safety accidents are still in a high incidence stage. Based on the investigation and summary of safety risk events and their causes in urban rail transit engineering construction at home and abroad, this paper fully combines the current national security management policies, introduces the "dual control" concept of safety risk classification and hidden danger investigation, and develops the intelligent monitoring system platform for urban rail transit engineering construction based on advanced technologies such as intelligent Internet of Things, 3D visualization, and artificial intelligence. It realizes the intelligent collection and analysis of engineering field monitoring data, the dynamic early warning management of engineering risk sources, the process embedding "dual control" mechanism of safety risk and hidden danger investigation, the real-time supervision of large equipment operations such as shield and hoisting, and the real-time control of high-risk operation sections such as contact channels. At the same time, the traceability and assessment management of the safety supervision process are strengthened. The parties involved in the project can realize the synchronous sharing of information through the platform and improve the efficiency of on-site safety and quality control.

\section{Introduction}

Urban rail transit is the main traffic in China. The development of urban rail transit is of great significance to relieve the pressure of urban public transport, promote urban construction and promote the economic development of related industries, improve the travel and living quality of citizens, and improve the urban environment. Because it is mostly constructed in the middle of prosperous area of city, affected by many factors, such as the ground environment, geological conditions, construction conditions, and construction technology, large-scale network construction means that it will be confronted with huge safety risks, vulnerabilities, and management issues. In view of this, the national construction department has issued a number of opinions and regulations, which further clarified the requirements of the dual prevention mechanism of safety risk control and risk investigation and management in engineering construction [1-5]. In addition, it was pointed out in the outline of the 13th Five-Year National Informatization Plan (in China) that it is necessary to improve the informatization level of construction industry, enhance the integrated application of BIM, big data, intelligence, real-time 
communication, cloud computing, Internet of Things, and other information technologies, and build an integrated supervision platform. Based on the above requirements, in view of the safety supervision of rail transit engineering, the research and development of information intelligent supervision platform is imminent.

At present, in view of the construction and management of urban rail transit projects, it can greatly improve the efficiency of management by establish the risk management and governance system which is information-based, visual, and intelligent [6-8]. Many scholars and institutions at home and abroad have also carried out research and application in related fields. In terms of security risk management, based on cost of safety (COS) theory and analytic hierarchy process (AHP), Aminbakhsh et al. [9] proposed a priority assessment method for security risk in construction engineering. Yoo et al. [10] forecast and evaluated the impact of the expansion project of Seoul Metro Line 3 in South Korea on the surrounding environment and possible risks by GIS and artificial neural networks. Ding and Zhou [11] established an urban subway safety risk early warning platform which automatically realizes the identification, evaluation, and early warning of engineering safety risks by data fusion model and which has been applied to Wuhan City subway construction project management. Li et al. [12] put forward the subway construction safety risk identification system and early warning system by BIM platforms. Aiming at the risk in subway construction, Yang et al. [13] developed a subway construction dynamic safety risk management and control information system and a supporting mobile phone inspection APP. Shen et al. [14] developed the Chengdu shield construction safety risk management information system which integrates the construction parameters, monitoring data, and live video surveillance of shield at all working points in the city and which has automatic reminder functions and perfect early warnings and disposal and alarm working mechanism for significant risky sources in shield construction. Wei et al. [15] established a $2 \mathrm{D} / 3 \mathrm{D}$ visualization web platform which makes use of sensors to collect data from different angles and visualizes geological parameters and TBM parameters to predict potential risks in TBM construction. In terms of risk investigation and management, Ding [16] proposed a risk management system based on the classification, investigation, evaluation, reporting, and governance of risk. Moreover, on the basis of the model, the Beijing rail engineering safety and quality risk management information platform was jointly developed. Zhou et al. [17] developed a risk detection information system based on wearable devices with risk identification function and Internet data transmission technology, and the system was used in Wuhan subway engineering. Based on the shortcomings of current risk management system, Gu et al. [18] constructed a risk management system according to the closed-loop management theory which classifies risk in accordance with level, grade, and profession and proposed a six-link closed-loop management model. In addition, Tianjin, Nanning, Shenyang, Hefei, and other places have also carried out the research and application of the safety risk management information system for the construction of rail transit projects [19-25].

In the application, some shortcomings of the existing platform have gradually emerged, mainly as follows: the platform has single function, the specialization of data analysis and risk prediction is not enough, and the safety risk management system and hidden danger investigation system are independent of each other. In addition, existing platforms often focus on single construction task, single component, or single security risk status, and thus it cannot aggregate and integrate multisource information in real time, it has not yet realized the integrated control of construction, operation, and maintenance, and it lacks management and control of major safety risk nodes such as lifting and hoisting and refinement of big data analysis modules and key indicators; therefore, it is impossible to realize overall and dynamic security risk management and risk investigation. Currently, the dual prevention content of security risks and hidden danger inspection required by national policies, laws, and regulations has not yet been embedded. Combining the above deficiencies, on the basis of fully understanding the relevant policies of national security management and emergency management, the basic theory of risk control, and the rules of hidden danger investigation and management, the authors focus on the overall relevance and unity of security risk management and hidden danger investigation and management. Combined with the requirements of the State Council to implement the dual prevention mechanism in the field of high-risk industries, this paper studies the integration of safety risk intelligent assessment, hidden danger investigation and management, intelligent data monitoring, shield and large lifting equipment management, patrol and video monitoring, and key risk nodes and contact channel safety management and control.

\section{Overall Design of the Platform's Operating Mechanism}

2.1. Business Requirement Analysis. Based on the above analysis and the understanding of risk management theory, risk management mainly realizes the risk prediction before engineering construction, puts forward the process precontrol measures, and implements the precontrol measures in the construction process, namely, risk control. Hidden danger investigation mainly conducts regular investigation on the risk precontrol measures proposed before in the process of engineering construction to ensure that the measures are in place. The developer conducted in-depth research of the intelligent monitoring system platform of risk management and hidden danger control based on the underlying monitoring technology of IOT in order to improve the overall safety and quality of urban rail transport network construction. 
2.2. Overall Design of Operating Mechanism. Based on the foresaid research, taking engineering risk control as the principal line, the overall operating mechanism of this platform has established the corresponding dual control for hidden danger detection and management. On the basis of the static risk rating evaluation in the preparatory stage of the construction, the major risk sources and their control were viewed as the key of hidden danger investigation. On top of that, all major risk sources were ensured to be under effective control with multidimensional monitoring information including supplementary data, construction parameters, and site inspection. In addition, the risk source level was dynamically adjusted for larger hidden danger and early warning alarm in the process of hidden danger detection and risk source monitoring. The specific dual control design of risk and hidden danger management is shown in Figure 1.

2.3. Integrated Design of Warning and Alarm Mechanism. Combined with the characteristics of rail transit construction and safety risk control, this platform developed and designed a four-color early warning and alarm mechanism for engineering risk monitoring based on multidimensional data sources. The blue warning corresponding project is in the state of concern, the yellow warning corresponding project is in the state of control, the orange warning corresponding project is in the state of alarm and has not been effectively controlled, and the red warning corresponding project is in the state of emergency. Among them, the judgment basis for the above warning is as follows:

(1) Red warning: monitoring data seriously exceed the standard or monitoring data have great mutations. Combined with the on-site and surrounding environmental inspection, it is comprehensively judged as an unacceptable risk, and the agency is in the critical state of emergency.

(2) Orange warning: the monitoring data reach the level of engineering alarm. Combined with the site and surrounding environmental inspection, it is comprehensively judged that the project is not willing to accept risks, and the project is in an unsafe state. The site must immediately take control measures.

(3) Yellow warning: the monitoring data reach the level of engineering alarm. Combined with the site and surrounding environmental inspection, it is comprehensively judged as an acceptable risk, and the site must take preventive measures.

(4) Blue warning: the monitoring data reach the level of monitoring warning and monitoring alarm. It is necessary to remind all parties to pay attention to the continuous change of the monitoring data. When necessary, preventive measures should be taken on the scene.

The explanation of the early warning "double control" index is as follows: when the cumulative change or two-day change rate exceeds $85 \%$ of the alarm value or when the onsite inspection is abnormal, the system starts early warning. Monitoring alarm: when one of the "double control" indicators (cumulative change and change rate) exceeds the alarm value or when the on-site inspection finds abnormalities. Engineering alarm: the monitoring data exceed the cumulative alarm value and are still not convergent (the change rate exceeds the alarm value for three consecutive days) or the cumulative value has exceeded the control value given by the design or when the abnormal situation is found in the field inspection.

This mechanism can realize the integrated early warning and alarm of monitoring data, patrol inspection, hidden danger investigation, video monitoring, large equipment monitoring, and quality defect monitoring. At the same time, the corresponding dynamic level adjustment of risk sources can be matched to truly realize the effective dynamic control of the whole process of key risk sources. Based on GIS map, the real-time adjustment and display function of dynamic level of risk sources in the whole network can be realized. The detailed design of early warning and alarm mechanism is shown in Figures 2 and 3.

\section{Overall Design of the System's Framework}

The framework design of the platform's system adopted the latest computer software development technology and mainstream framework design while ensuring the system scalability and easy maintenance and other requirements. Programming languages Java and .Net should be given preference. The framework was designed and developed with MVC model to realize the display separation of logic, data, and interface. The platform's software modules should adopt hierarchical framework and object-oriented concept to reduce the coupling between modules as much as possible, while the detailed design must consider the scalability. The overall design of the platform's technical framework is shown in Figure 4.

\section{Overall Design of the System's Function}

In view of the platform's overall requirements described in Section 2.1, the main considerations in terms of functional design of the platform's framework cover intelligent multidimensional supervisory measurement, large equipment safety monitoring (shield informational monitoring, crane hoisting monitoring, video monitoring, and so on), overall security risk control module, GIS map overview and information integration display module and other modules with their respective function of geographic information display, engineering information display, red and yellow cards, every project has a file, message transfer, and so on. The overall functional design of the systems' framework is shown in Figure 5.

\section{System Development and Application}

Based on the overall design of the platform's operation mechanism, framework, and function, the platform's 


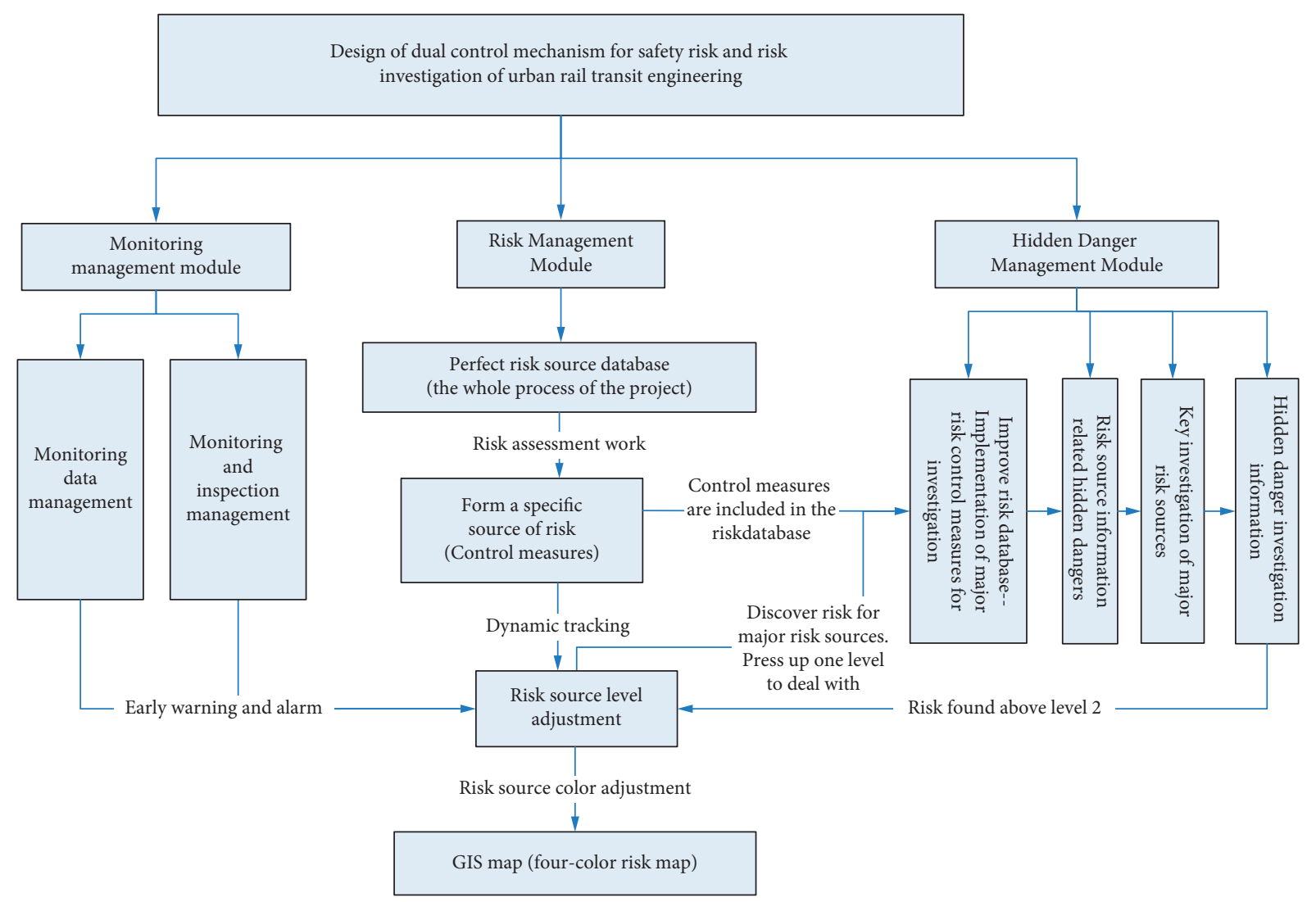

FigURE 1: The design diagram of the dual management and control operation mechanism for the overall risk of the system platform.

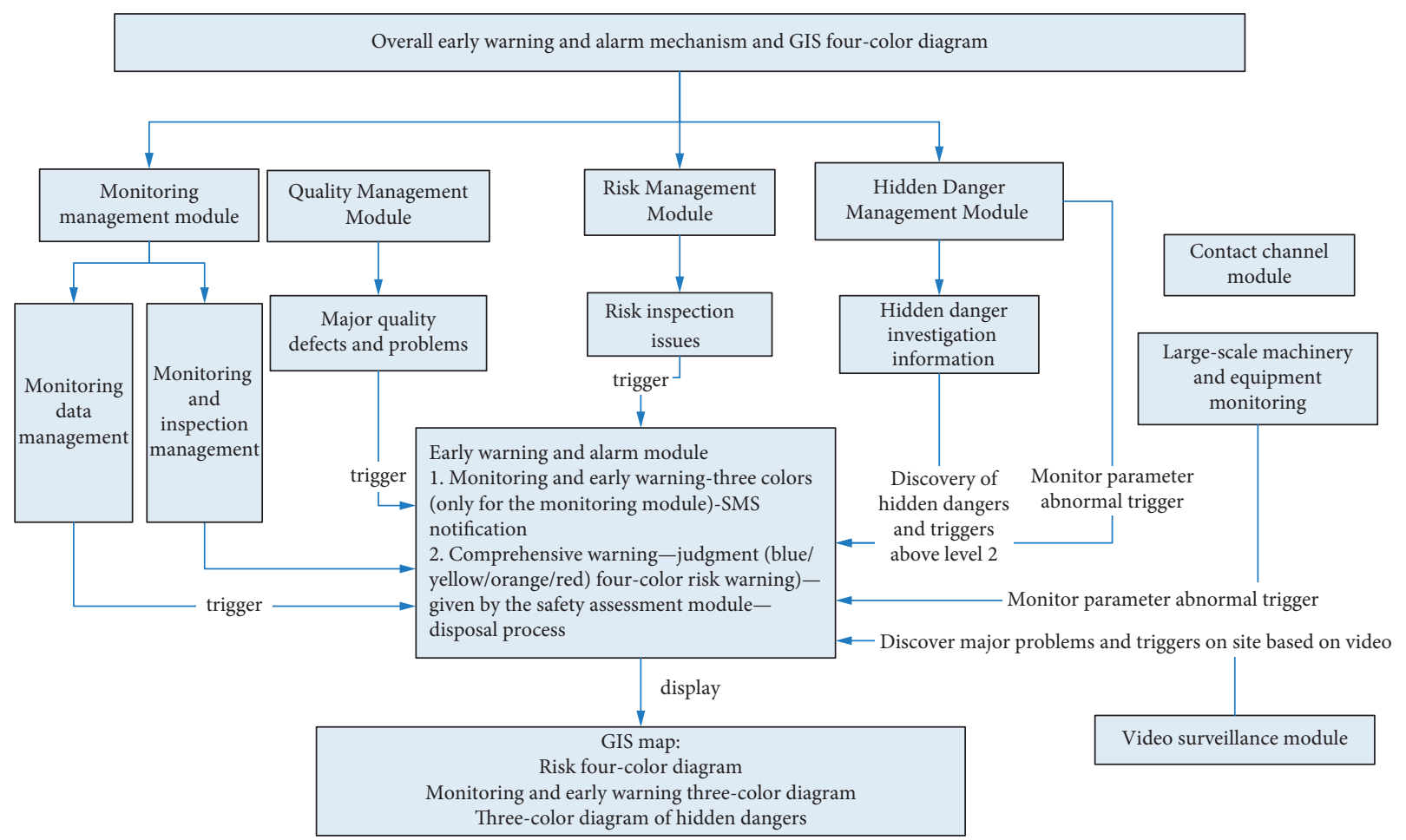

FIGURE 2: Design diagram of the overall early warning and alarm mechanism based on GIS four-color display. 


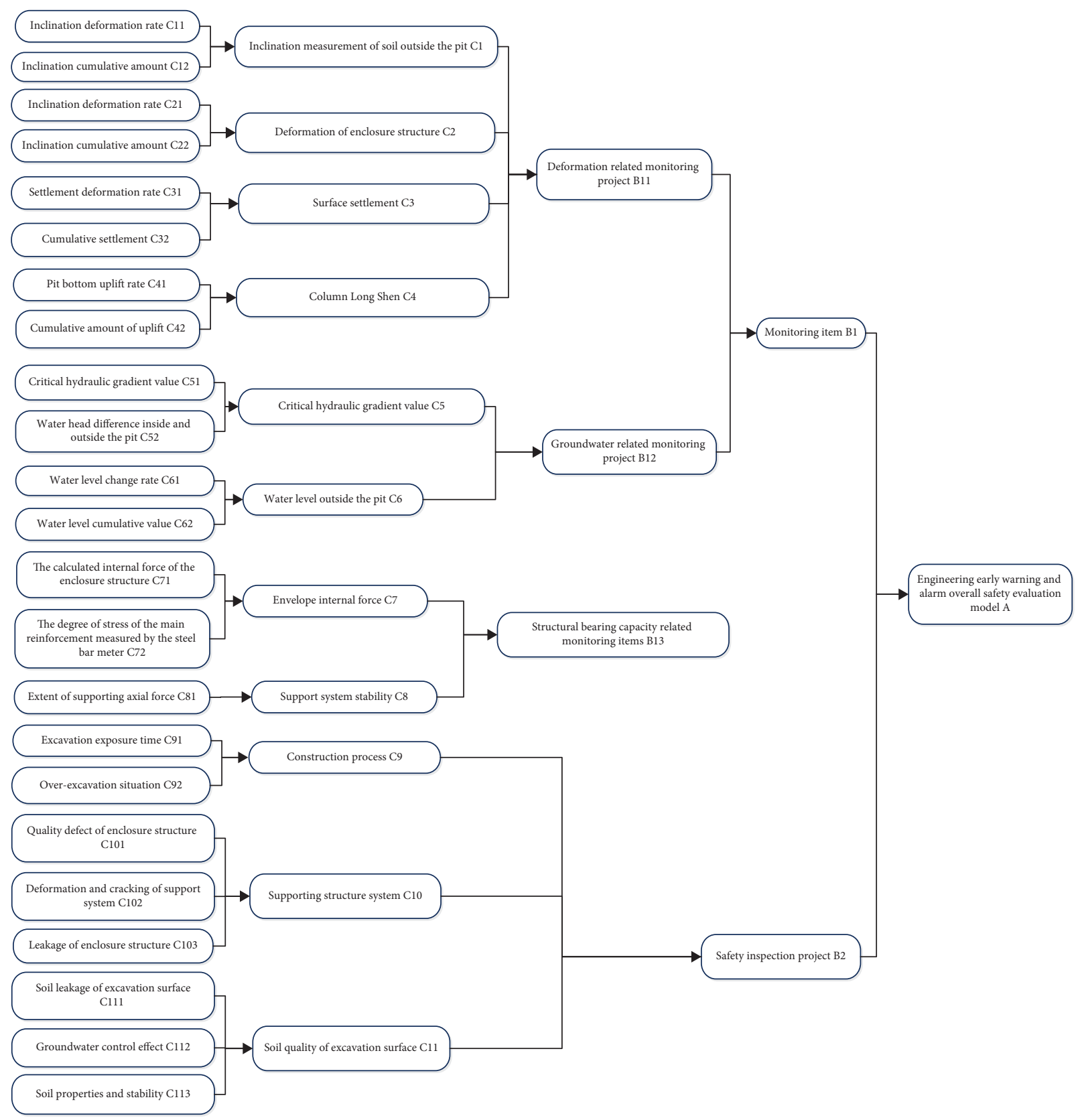

FIGURE 3: Overall safety evaluation model of engineering early warning based on index analysis.

intelligent system of risk and hidden danger monitoring for urban rail transport project has been developed and formed on account of the full investigation and absorption of the advantage of the existing systems of major cities, and it was fully applied in the third-round project of Hangzhou subway construction, which achieved sound effect and economic benefits.

5.1. Portal Web and GIS. By integrating the basic data of each functional module, this module has realized info category display, model navigation, important message notification, task centralization, and other functions, so users need not switch back and forth between different functional modules.
Through GIS layer, it realized the multilayer display of more than five major themes in the same interface, such as construction state, risk tendency, hidden danger situation, warning alarm monitoring, and shield excavation, which can control the overall safety of urban rail transport construction.

Compared with other platforms, this module adds BIM 3D display (Figure 6) and engineering risk GIS 4D graph.

5.2. Intelligent Monitoring Measurement. Intelligent monitoring measurement module can realize at each work site the collection, integration, analysis, graphical display, trend forecast, and specified format report output of monitoring data. 


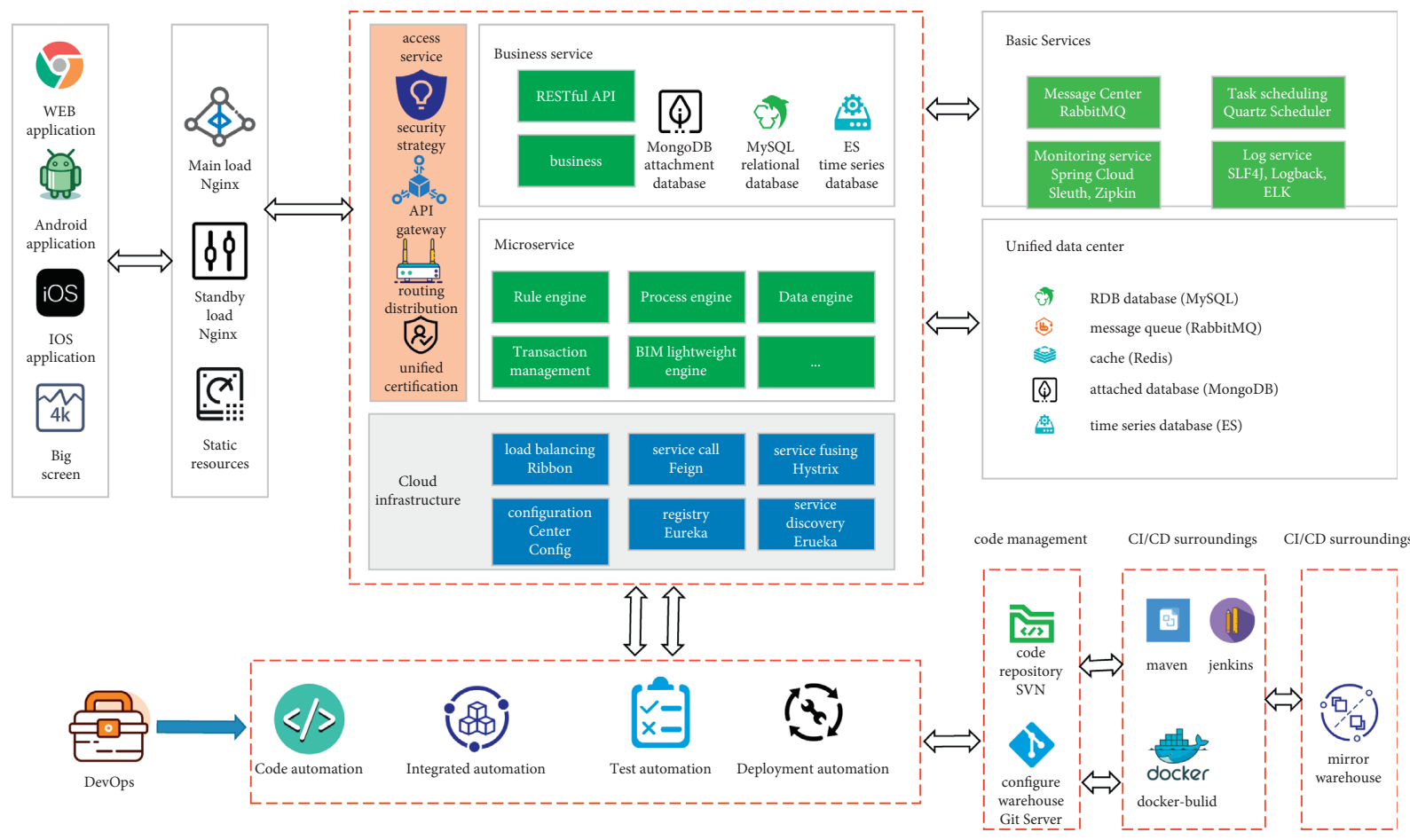

FIgURE 4: The architecture design drawing of the intelligent monitoring system for the investigation of safety risks and hidden dangers in urban rail transit engineering construction.

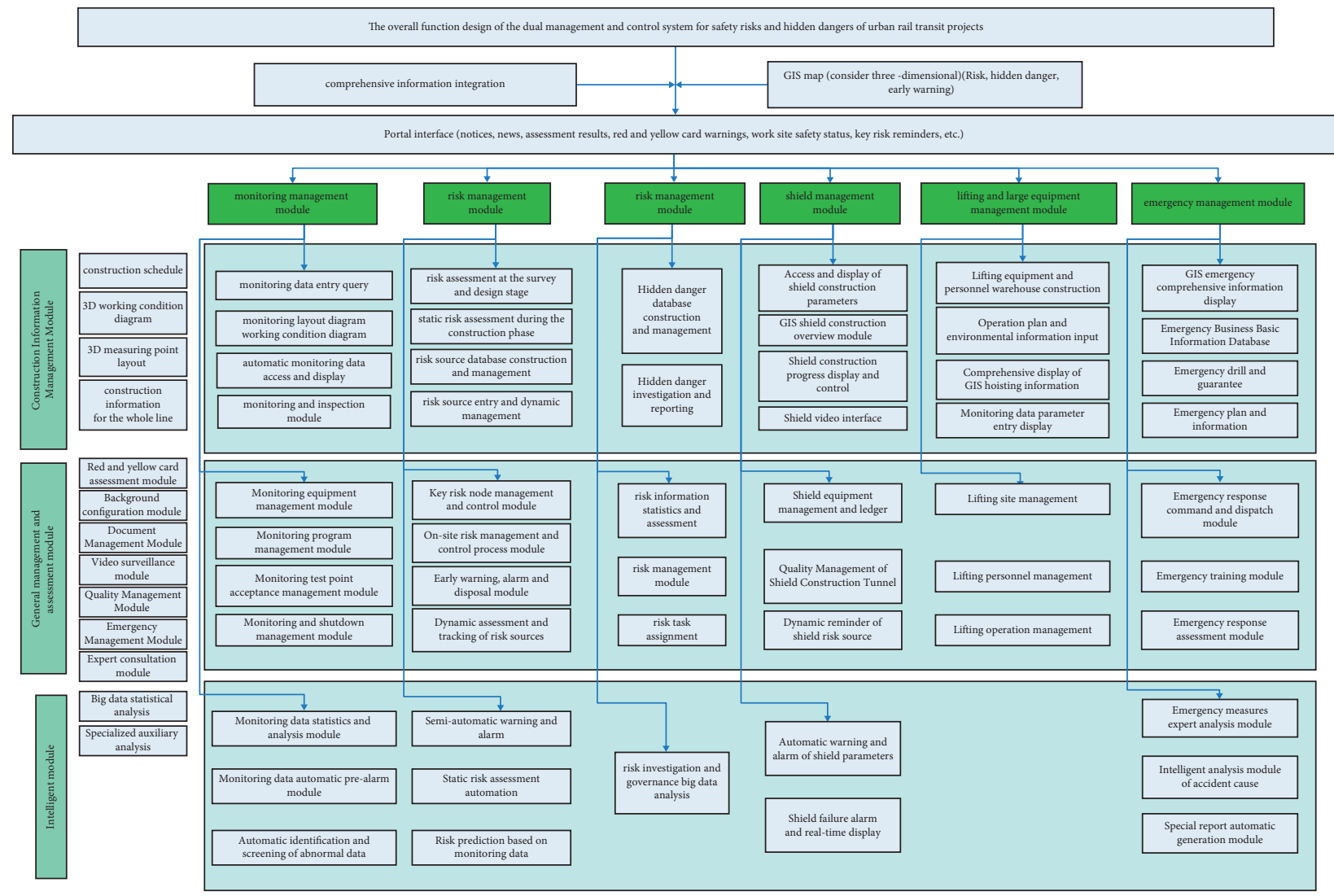

FIGURE 5: The architecture design of the intelligent monitoring system for the investigation of safety risks and hidden dangers in urban rail transit engineering construction. 


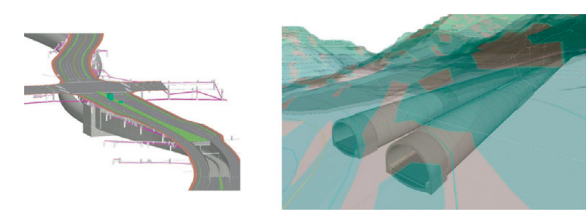

FIGURE 6: Engineering BIM 3D display model.

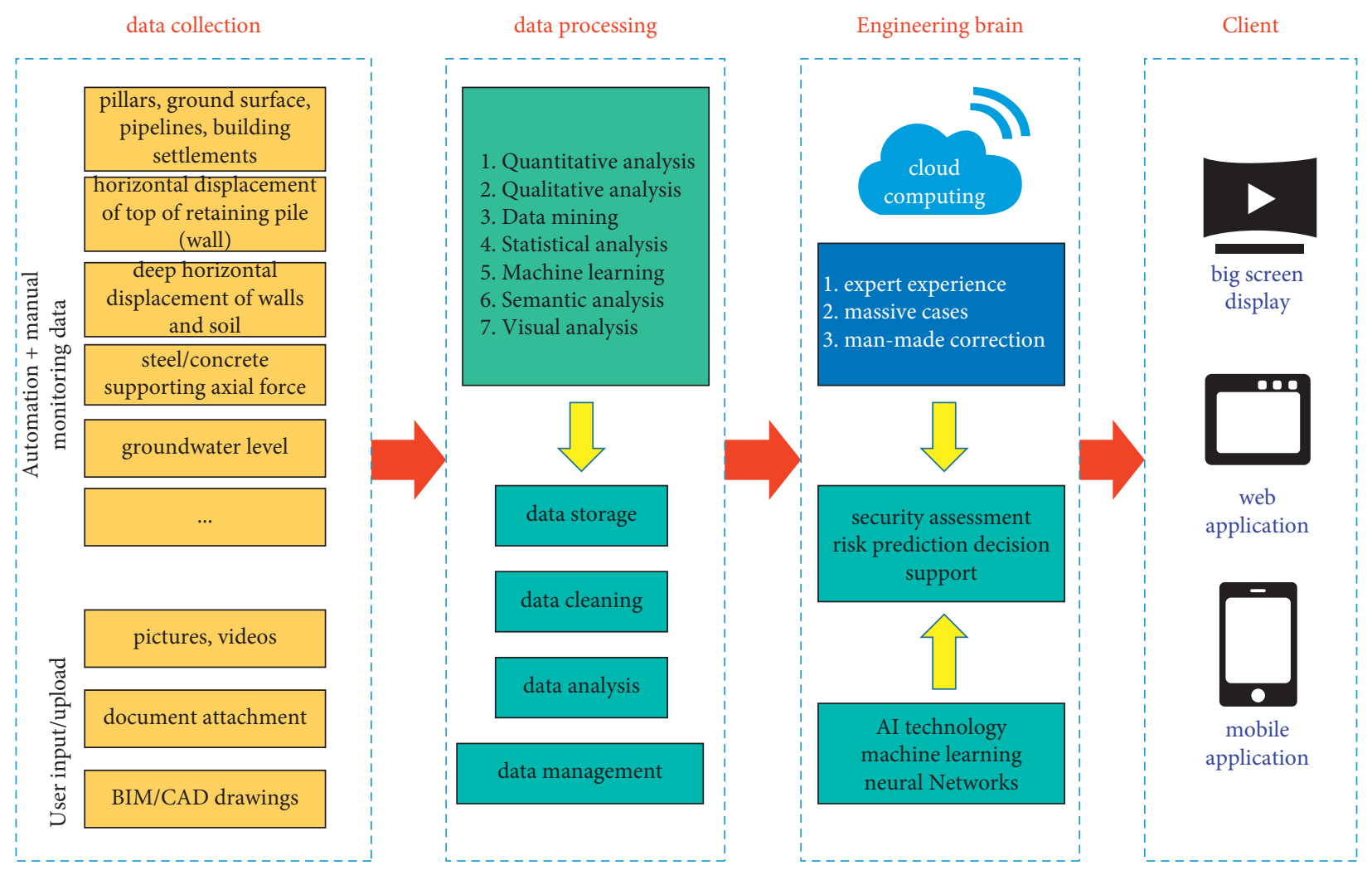

FIGURE 7: Monitoring and measurement module business flowchart.

The main idea is to integrate the IOT data in the safety monitoring system and manual monitoring data to analyze the relevant monitoring data at each work site in accordance with business needs using cloud computing, big data analysis, and other technologies, which can achieve data recording, graph drawing, automatic contrastive analysis of monitoring data, automatic warning for overrun, and the evaluation of the work site safety through monitoring data. The flowchart is shown in Figure 7 . In the layer of data display, monitoring point data anomalies and their influence coverage are displayed in $3 \mathrm{D}$ visualization with BIM technology.

5.3. Intelligent Monitoring of Shield Machine. Based on multiple heterogeneous data analysis and access technology to parameters of large shield tunneling machine of all brands, the module has acquired comprehensive access to PLC control parameters of well-known shield machines both at home and abroad, such as Herrenknecht, China Construction Tunneling Equipment, China Railway Engineering Equipment, Okumura, and Daye. While ensuring network information security, it can realize multilevel transmission stably and efficiently from LAN to Internet and has functions such as shield parameter online view, historical data review and statistical analysis, and so on. When the parameter exceeds the limit, it triggers automatic alarm and releases early warning notification in the form of SMS and APP. In addition, the shield module GIS can also achieve the dynamic display of shield machine tunneling path and real-time location through algorithms and correlate the major risk sources around the interval and the automatic release of risk forecast by the system during the traversal, which drew the attention of all parties.

5.4. Crane and Large Equipment Hoisting Monitoring. This module mainly includes general information, library manager, hoisting log, safety control, and other submodules. It can realize the effective supervision of all kinds of crane and large equipment hoisting in the whole process.

5.5. Monitoring of Freezing Construction of Contact Channel. The key risk point monitoring module of freezing engineering in contact channel can realize 


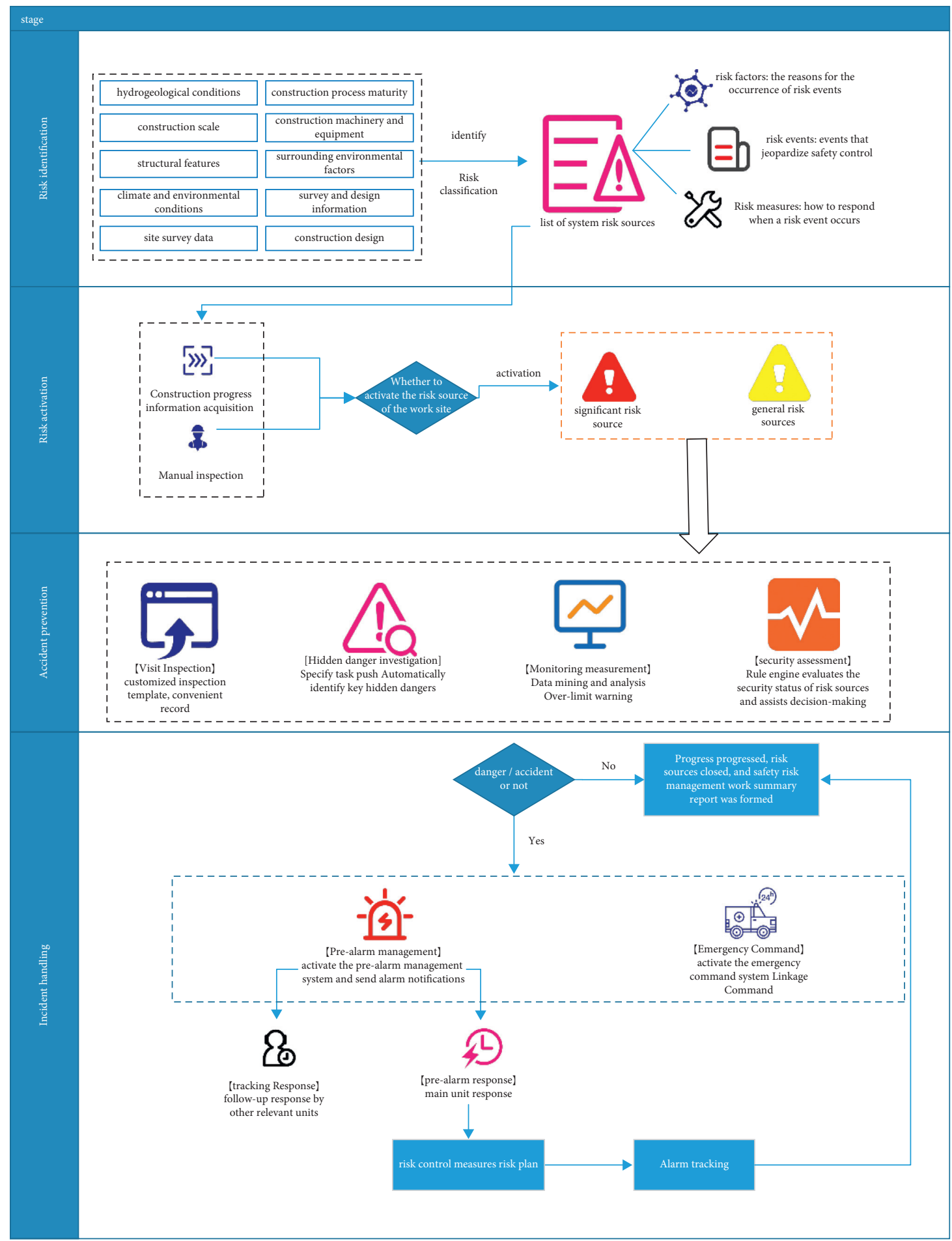

FIgURE 8: Security risk management and control process based on mechanism model.

automatic temperature data access, real-time temperature monitoring, automatic temperature abnormality prealarm, historical data query and statistics, aided safety assessment, freezing curtain calculation, and other functions.
5.6. Risk Management Module. This module is the core module of the system platform. Mainly based on the decision-making control of safety risk, it can identify and assess risks in the early stages of engineering construction, form control lists, and realize functions as dynamic risk control 
and early warning management combined with the construction of a risk source database, and the security risk management and control process is shown in Figure 8.

5.6.1. Risk Source Management in Work Site. The platform can form a project-wide dynamic risk source database according to the static risk assessment results, containing risk sources, factors, events, and measures. The work site risk source can form its control list based on the static risk assessment results and realize effective supervision of the work site risk sources through the system platform in the construction process.

5.6.2. Safety Assessment and Early Warning. The safety assessment submodule allows daily risk assessments to be carried out to grasp the safety type of each work site. The page comprehensively displays information such as project overview, work condition diagram, and measuring point layout while associating risk source information according to construction progress.

Early warning submodule can show the warning information of each work site, including the warning level, time and status, and so on. The corresponding alarm report can be viewed in the attachment. In the search bar, you can filter searches according to the warning time and status as required.

\subsection{Hidden Danger}

5.7.1. Hidden Danger Investigation Module. Integrated information module for hidden danger, through filtering time, can count the number of hidden dangers at all levels and form a pie chart and can compute the hidden danger rectification and form a bar chart so as to get detailed hidden danger statistics of each line according to the frequency of investigation below the chart.

\subsubsection{Hidden Danger Investigation and Management} Module. The hidden danger check screen allows participants to add a hidden danger investigation record by creating a new task. The top of the page displays the number of each investigation status by different colors, and we can filter the qualified records by unit, situation, frequency type, start time, and other information.

In the hidden danger management module, the top of the page displays the status and quantity of hidden danger list by different colors, and we can filter the qualified lists by unit, hidden danger level, start time, and other information. One can check the specific information of the list and the progress of rectification through the "operation" button, and the hidden danger will be shut after the rectification is completed.

The hidden danger statistics module can count the number of various hidden danger levels by filtering lines and times and form the corresponding bar chart and pie chart.
5.7.3. Hidden Danger Assessment. In the hidden danger assessment module, the rules of deducting points in the hidden danger management of Metro Group are inputted to the system to realize automatic assessment on the platform. You can select the work site to view the score through the left navigation tree. The system will show the total score and the reasons for points deduction in detail, and the specific deduction of points will pop up when you click on the button.

5.8. Overall Operation of the System. As of December 31, 2020 , the platform has been widely used in the third-round project of Hangzhou subway construction. At present, the monitoring module has reached a daily average processing of more than 50,000 monitoring data, with a total of 594 early warning messages; the video monitoring module has accessed a total of 261 work sites, with a total number of 1,783 videos; the crane hoisting module has recorded a total of 2,979 sets of equipment and 2,312 operators; the shield information module has accessed 332 shield machines and monitored nearly 120 shield constructions at the same time during the peak period of construction; the hidden danger investigation and management module rectifies and shuts more than 3,000 hidden dangers on average per month. When the platform was applied in the actual construction, the system has given full play to its role in improving the quality and efficiency of safety management in the process of intelligent multidimensional monitoring of engineering safety, static risk assessment and dynamic risk source control, hidden danger investigation and management of risk unit, comprehensive multidimensional information forewarning, and real-time information delivery. At the same time, it gave an excellent model and demonstration to the dual preventive work mechanism of risk rating control and hidden danger management for domestic rail transport projects, which brought about significant economic and social benefits and high promotion and application value.

\section{Summary}

The platform for the first time integrated and embedded into the system the dual control mechanism of safety risk control and hidden danger management, realizing the intelligent integration of multidimensional data based on the information of engineering safety monitoring, inspection, hidden danger investigation, major key points monitoring, shield and large equipment safety control, dynamic contact channel freezing temperature field, video and access control, engineering hidden danger investigation and management, etc. It has also realized the functions of prediction and prevention of key risk sources from the early stage of construction, of early warning and alarm, and of dynamic rating and control of the process risk, ensuring the whole process safety in the construction. The platform design generally reflected the concept of high security and data modelling, considered the overall information integration, achieved the automatic collection system, and realized the management process embedding, the 3D display, the 
information-based work condition display, the project profile display, and other functions, which has great economic and social benefits.

\section{Data Availability}

No data were used to support this study.

\section{Conflicts of Interest}

The authors declare that they have no conflicts of interest.

\section{Acknowledgments}

This study was supported by the Key R\&D Program of Zhejiang Province Science and Technology Department (no. 2020C01102), "R\&D and industrialization of special equipment and key components for rail transit R\&D and application of key technologies for subway tunnel protection and monitoring system and disease prevention," and Zhejiang Construction Scientific Research Project (no. 2018K140), "Platform of the development and application of the Hangzhou metro construction risk systematics control and risk inspection and governance based on the IOT.”

\section{References}

[1] F. R. Luo and W. F. Cao, Safety Risk Management System of Beijing Rail Transit Project, China Railway Publishing House, Beijing, China, 2013.

[2] G. W. Liu, "Research and application on security and risk management information system for guangzhou metro project construction," Railway Computer Application, vol. 21, no. 5, pp. 29-33, 2012.

[3] Z. H. Shi, "Strengthening the development and operation management of urban rail transit projects," Urban Rapid Rail Transit, vol. 30, no. 1, pp. 1-3, 2017.

[4] P. Lyu, "Present situation and development of security technology for urban rail transit construction," Urban Rapid Rail Transit, vol. 30, no. 1, pp. 7-11, 2017.

[5] L. Q . Wang, "Research and practice on informatization of safety management for urban rail transit project in Guangzhou," Journal of Safety Science and Technology, vol. 12, no. 6, pp. 169-174, 2016.

[6] X.-S. Chen, Z.-H. Xu, B. Xiao-hua, X. Wang, and Y. Fu, "Challenges and technological breakthroughs in tunnel construction in China," China Journal of Highway and Transport, vol. 33, no. 12, pp. 1-14, 2020.

[7] Q. H. Qian and X. L. Rong, "State, issues and relevant recommendations for security risk management of China's underground engineering," Chinese Journal of Rock Mechanics and Engineering, vol. 27, no. 4, pp. 649-655, 2008.

[8] Q. Qian and P. Lin, "Safety risk management of underground engineering in China: progress, challenges and strategies," Journal of Rock Mechanics and Geotechnical Engineering, vol. 8, no. 4, pp. 423-442, 2016.

[9] S. Aminbakhsh, M. Gunduz, and R. Sonmez, "Safety risk assessment using analytic hierarchy process (AHP) during planning and budgeting of construction projects," Journal of Safety Research, vol. 46, pp. 99-105, 2013.

[10] C. Yoo, Y.-W. Jeon, and B.-S. Choi, "IT-based tunnelling risk management system (IT-TURISK) - development and implementation," Tunnelling and Underground Space Technology, vol. 21, no. 2, pp. 190-202, 2006.

[11] L. Y. Ding and C. Zhou, "Development of web-based system for safety risk early warning in urban metro construction," Automation in Construction, vol. 34, pp. 45-55, 2013.

[12] M. Li, H. Yu, H. Jin, and P. Liu, "Methodologies of safety risk control for China's metro construction based on BIM," Safety Science, vol. 110, pp. 418-426, 2018.

[13] C.-C. Yang, N. Wang, and Y. Lei, "Construction of information system of dynamic risk management for subway Construction," Safety and Environmental Engineering, vol. 24, no. 5, pp. 115-119, 2017.

[14] W.-P Shen, J. Zhang, and B. Yuan, "Research of safety risk management information system for shield tunneling construction in Chengdu metro based on intelligent interconnection technology," Chinese Journal of Rock Mechanics and Engineering, vol. 38, no. S2, pp. 3822-3832, 2019.

[15] L. J. Wei, M. Khan, O. Mehmood et al., "Web-based visualisation forlook-ahead ground imaging in tunnel boring machines," Automation in Construction, vol. 105, Article ID 102830, 2019.

[16] S. K. Ding, "Detection and treatment of hidden construction quality risks in urban rail transit," Urban Rapid Rail Transit, vol. 25, no. 6, pp. 43-47, 2012.

[17] C. Zhou, T. Ye, and L. Xing-gui, "Wearable devices for hidden danger identification and controlling in subway tunneling construction," Journal of Civil Engineering and Management, vol. 33, no. 2, pp. 30-35, 2016.

[18] X. Gu, D. Li, L. Zhang, and L. Ma, "Establishment and execution of potential safety hazard control system in Beijing subway," Urban Mass Transit, vol. 18, no. 7, pp. 9-13, 2015.

[19] C. Zhou, Study on the Design and Application for Safety Control System in Metro Construction Project, Huazhong University of Science and Technology, Wuhan, Hubei, China, 2007.

[20] G. Liu and H.-B. Cui, "Analysis and construction of safetyrisk-management information system for metro construction based on GIS," Architectural Technology, vol. 42, no. 6, pp. 554-556, 2011.

[21] Y-Z. Wang, Research on the Application of Security Risk Contorl Information Technology in Hefei Metro Line 2, Lanzhou Jiaotong University, Lanzhou, China, 2018.

[22] W.-j. Zhu, R. H.. Weng, H. Q. Li, and X. Xi, "Development of metro hidden hazard investigation system based on mobile internet," Urban Mass Transit, vol. 22, no. 11, pp. 67-70, 2019.

[23] Z. Ding, X.-j Wei, and G. Wei, "Prediction methods on tunnel-excavation induced surface settlement around adjacent building," Geomechanics and Engineering, vol. 12, no. 2, pp. 185-195, 2017.

[24] Z. Ding, X.-j Wei, X. Zhang, and X.-s Yin, "Analysis of the field monitoring data on soil movements and adjacent building settlement due to shield tunnelling," Engineering Computations, vol. 36, no. 4, pp. 1219-1237, 2019.

[25] X. Yin, R. Chen, F. Meng et al., "Face stability of slurry-driven shield with permeable filter cake," Tunnelling and Underground Space Technology, vol. 111, Article ID 103841, 2021. 